\title{
Assessing the Effect of Public Transfer Payments on the Vulnerability of Health Care Poverty in Rural Households in China
}

Yali Li ( $\square$ liyali_maxspeci@outlook.com )

Jiangxi Normal University

\section{Research Article}

Keywords: Andersen model, Vulnerability to poverty, Multidimensional poverty, Multivariate logistic analysis, Public transfer payment, Chinese rural households

Posted Date: August 9th, 2021

DOI: https://doi.org/10.21203/rs.3.rs-764110/v1

License: (9) This work is licensed under a Creative Commons Attribution 4.0 International License.

Read Full License 


\title{
Assessing the effect of public transfer payments on the vulnerability of health care poverty in rural households in China
}

\author{
Yali $\mathrm{Li}^{1,2 *}$
}

\author{
${ }^{1}$ School of Finance, Jiangxi Normal University, Nanchang, 330013 China. ${ }^{2}$ North Carolina State \\ University, P. O. Box 8005, Raleigh, NC 27695-8005 USA \\ * Corresponding author: liyali_maxspeci@outlook.com
}




\title{
Assessing the effect of public transfer payments on the vulnerability of health care poverty in rural households in China
}

\author{
Yali $\mathrm{Li}^{1,2 *}$
}

\begin{abstract}
Background: Since the 18th National Congress, China has completed the task of eliminating absolute poverty. However, the risk of health care for potential sub-health workers and the elderly in rural households has also increased, and government public transfer payments play an important role in reducing the vulnerability of rural families to health care poverty. Assessing the effectiveness of government public transfer payments in reducing the vulnerability of rural families to health care poverty will help the public sector to develop more accurate policies to meet the different needs of rural households for health care.
\end{abstract}

Methods: The data were derived from the 3rd 、4th and 5th National Survey of the China Family Panel Studies conducted in 2010. The annual study sample was 5,574 rural households, with a total sample of 16,722 rural households during the three-year study period. We assess and compare the multidimensional poverty and the vulnerability to health care poverty of rural households. Two series of multivariate logistic regression models were further undertaken to assess the effect of government public transfer payments before and after adding the income elasticity of health care needs on improving the vulnerability of rural families to health care poverty.

Results: The study found that when setting the poverty line at $\$ 1.90$ and $\$ 3.20$, rural households in the three research years expected a higher vulnerability to health care poverty than their actual incidence of multidimensional poverty in health care, and higher poverty vulnerability in the eastern region than in the western region. A series of multivariate logistic models evaluated the effect of government public transfer payment on improving the vulnerability of rural health care poverty and found that it is difficult for the government to fulfill the effect of public transfer payment without considering the difference of rural households' demand for health care.

Conclusions: At present, the imbalance of development between urban and rural areas in China is increasing, and rural families with heavy economic burdens are facing the risk of sub-health such as potential chronic illness. Our analysis emphasizes the importance of government departments in improving the targeting of public transfer payments to reduce the vulnerability of health care poverty in rural households.

Keywords: Andersen model, Vulnerability to poverty, Multidimensional poverty, Multivariate logistic analysis, Public transfer payment, Chinese rural households

\section{Background}

Since the 18th National Congress has been held, after eight years of struggle, by the end of 2020, following the previously formulated goal of eliminating absolute poverty in an all-around way, China has completed the task of eliminating absolute poverty. According to official statistics, 98.99 million rural poor people were all lifted out of poverty under current standards, 832 poor counties removed from poverty counties, and regional overall poverty resolved, completing the arduous task of eliminating 
absolute poverty [1]. With the comprehensive victory of eliminating absolute poverty in a new era in China, it is necessary to establish a long-term and stable mechanism to continue to consolidate the achievements of promoting the overall eradication of absolute poverty, and China's comprehensive development strategy to promote rural all-round development is an important means to effectively consolidate the achievements of the comprehensive eradication of absolute poverty. However, with the overall dramatic reductions in poverty, headcounts have increased in public services inequality such as health care , medical security, etc., which has arisen within as well as between urban and rural sectors. The overall increase in inequality in health care and health care has allowed China to move from one of the most equal societies in two decades to one of the most unequal societies in Asia [2]. Additionally, the gap between rural medical care and medical security supply has helped rural families to be in the plight of multi-dimensional poverty in health care [3]. In assessing overall progress towards development goals, the distinction between poverty is largely transient or chronic [4]. In terms of the distribution of potential income or consumption outcomes, happiness is framed and alternative indicators are proposed to measure the effectiveness of development policies: the vulnerability of households to poverty. Vulnerability is a forward-looking, forward-looking measure of a family's vulnerability to adverse socioeconomic outcomes.

Under the social background of an aging population, the number of elderly people in rural areas is growing rapidly, and the imbalance caused by the supply and demand of health services and health care resources in many areas poses a health and aging risk to the elderly in rural areas [5]. At the same time, in the modern era of high-stress economic development, the main workers in the family may have chronic diseases, bronchitis, and other sub-healthy physiques due to long-term work due to long periods of exertion and lack of adequate rest, these rural families are prone to become potentially poor families or vulnerable poor families. The impact of health risks on poverty vulnerability includes both the micro and macro dimensions. At the micro-level, health risk shocks usually refer to the loss of family benefits caused by chronic diseases in the elderly or long-term working groups in the family over a specific period [6]. At the macro level, it refers to the risk impact of regional or global epidemic outbreaks, such as the health impact on rural households under the current global new crown outbreak risk impact [7]. These health risks tend to contribute to the poverty vulnerability of rural households to health care. China has made remarkable achievements in the absolute eradication of absolute poverty, but there is still much work to be done in relative poverty eradication goals, as evidenced by the fact that the elderly and longterm working-age groups in rural households are vulnerable to the fragile impact of health and medical mechanisms, and that the reduction of economic assistance between families will increase the vulnerability of rural families to health care poverty. Therefore, effective analysis of the role and impact of government public transfer payments on improving the vulnerability of rural family health care to poverty, and the proposed fiscal policy and program to improve the vulnerability of rural family health care poverty will provide a scientific basis and method guidance for China and other countries to effectively prevent and cope with rural families falling back into poverty.

In this paper, we will use a methodology of vulnerability as expected poverty to quantify and assess the vulnerability of health care poverty, as household income may fall below the pre-specified poverty line in the future. Considering that the implementation of public mechanisms can have an impact on the well-being and subjective needs of policy beneficiaries. During the study period, we measured the income elasticity of rural households' demand for health care and used the multi-variable logistic regression model to evaluate and compare the marginal utility of the government's fiscal transfer payment to the rural family's health care poverty vulnerability before and after the inclusion of income elasticity of health care demands. It provides evidence to Chinese public service decision-makers whether the vulnerability of health care poverty in rural households is related to the different levels of demand for health care services, to gain an in-depth understanding of how to optimize the allocation of health care resources for rural families by public transfer payments, and proposes approaches to improving the vulnerability of poverty.

\section{Literature Review}


With the complexity and diversity of human development, the understanding of poverty tends to be diversified. [8] has pointed out that there are limits to identifying poverty in monetary terms alone, and that real poverty should be a denial of people's current viability, people crossing the minimum threshold for basic economic security and being trapped in other key areas of individual development, such as poverty vulnerability resulting from the shortcomings of public service policies in education, health care, etc. Transforming our World: The 2030 Agenda for Sustainable Development "was adopted by United Nation [9]. It was also stated that the goal of "non-poverty" refers to the comprehensive solution of social, economic, and environmental poverty in an integrated manner. To achieve multi-dimensional poverty alleviation, fiscal policy tools as the main means of improving poverty policy play an important role it. Some scholars think that public transfer payment has the function of alleviating the effect of income poverty and income redistribution to the poor and the extremely poor in general to a certain extent [10][11][12]. Moreover, there is some literature to explore its efficiency, some researchers believe that the target of fiscal transfer payments is accurate to the expected poverty reduction is efficient [13][14][15][16][17]. It should be noted, however, that fiscal transfer payments can often lead to reverse incentives in the failure of poverty targets or misery in the implementation of public policies, leading to inefficiencies in anti-poverty efforts. Through the anti-poverty status of 48 countries, Grosh carried out public transfer policy targeted efficiency research, and he found that in 122 transfer payment projects, 25\% of the transfer payment income is not accurately transferred to the poor, there is a significant inefficiency [18]. Dabalen evaluated the effects of Albania's anti-poverty public transfer policy in 1993 and used the method of Propensity Score Matching (PSM) to assess that the welfare status of beneficiaries of continuous acceptance of transfer income was significantly lower than that of the matching objects on the demand for public services, resulting in the inefficient state of public policy implementation [19]. Using repeated cross-sectional data from 1996-2003, Bargain analyzed the effects of poverty alleviation in Finland and found that the use of the wrong measurement tools had a direct impact on the welfare eligibility and efficiency of the targets being assisted [20].

Multidimensional poverty analysis allows public sector decision-makers to assess the impact of a given plan or policy afterward. However, there are good reasons to make policies and approaches to improving poverty more forward-looking and to consider their possible future impacts or outcomes [21][22]. Since anti-poverty policies became an important public policy in developing countries, researchers have found that the key to policy success lies in how to measure the vulnerability of poverty [23][24]. Vulnerability is the likelihood that at a given time in the future, an individual will have a level of welfare below some norm or benchmark. Chaudhuri defined the concepts of vulnerability and poverty (which is also multidimensional) as linked but is not identical, they thought vulnerability is an ex-ante (forward-looking) concept, not an ex-post one [25]. In summary, three theoretical methods for measuring the vulnerability of poverty have emerged in the literature: Vulnerability as Low Expected Utility (VEU)、 Vulnerability as Expected Poverty (VEP), and Vulnerability as Uninsured Exposure to Risk (VER). The VEU's measurement method was proposed by Ligon \& Schechter [26]. This measure measures the loss of well-being based on changes in utility and the vulnerability of poverty by the difference between the established level of equivalent consumption and the utility of consumption expectations. Later, he selected data from Bulgaria's 1994 survey panel and used food expenditure as a measure of consumption levels to control individual heterogeneous characteristics over time, including household income status, employment status, number of people receiving pensions or pensions, etc. And the results showed that $55 \%$ of the causes of poverty vulnerability in the country were from low income, $13 \%$ from synergy risk, $0.7 \%$ from heterogeneous risk and others from unexplained risk [26]. Thus, poverty and risk play a comparable role in reducing welfare levels. The poverty component is an integral part of poverty vulnerability, accounting for more than half of the overall vulnerability to poverty. Among the various types of risks that contribute to the vulnerability of family poverty, unexplained risks are the most important sources of vulnerability, so it is necessary to estimate the breakdown of heterogeneous risks. In recent studies, Klasen \& Waibel believed that among the various risks that contribute to the vulnerability of family poverty, the unexplained risk is the most important source of vulnerability, so it is necessary to estimate the breakdown of heterogeneous risks [23]. Grech's research on Europe also came up with a similar 
conclusion [27]. Wald thought that higher-frequency data should be used when considering the impact of risk [24]. Other scholars have found that the most useful data for chronic poverty are longer-term data, such as long-term time-series data or panel data on household consumption [26][23]. The measurement method of VEP is proposed by [28][29][25][30]. Subsequently, significant improvements were made by Klasen \& Waibel [23]. Pritchett et al. tried to measure the vulnerability of poor areas in Indonesia. They define poverty vulnerability as the likelihood that a family will fall into poverty in the coming months [28]. Also, by defining the poverty line as a constant that does not change over time, it represents a level of well-being consistent with the established level of expenditure, and the level of expenditure for each period is the actual expenditure adjusted for the price level, comparing it with the size of the poverty line. In their case study, they defined the probability of future poverty being higher than $50 \%$ as being vulnerable to poverty, so they set a threshold of 0.5 . In the study, they analyzed the regression data from Indonesia's two-phase panel and found that the proportion of the total population at risk of poverty vulnerability was much higher than that of the total poor, with 10 to $30 \%$ of the population at high risk of falling into poverty. In addition, differences in poverty vulnerability can be caused by different genders, different levels of education, different regions, different land ownership levels, different sectors of the head of household, and other sectors [31].However, from the measurement results, this study on "poverty vulnerability group differences" can only qualitatively judge whether households are poor and vulnerable, separating the more vulnerable families from the total population, without quantitatively studying the vulnerability of these families to poverty. Thus, it can only reflect the total number of vulnerable families in poverty, not the depth of vulnerability to poverty in each family [32]. Given the revision of the VEP measurement method, Celidoni pointed out that assuming that the risk of particularity is independently distributed at different times, considering that there is a common functional relationship between its degree of change and observable characteristics, and the fixed effect of the family can be obtained based on the three-stage Feasible Generalized Least Squares (FGLS) [33]. Further, Dutta proposed a composite measurement method that takes into account the level of the poverty line and the current standard of living, and set a baseline to measure poverty vulnerability [33]. The essential difference between VEP method and VEU method is that the change of utility of the latter reflects the loss of welfare level and infers poverty vulnerability, while the VEP method uses the estimate of income and consumption functions to infer poverty vulnerability. The VER measurement method is proposed by Dercon \& Krishnan, and by using three consecutive semi-annual data from rural households in Ethiopia, he derived cross-sectional poverty statistics that greatly underestimated the poverty vulnerability of households [34]. The VER method does not directly measure vulnerability, but rather represents the degree of vulnerability by a sensitivity factor, and does not separate the impact of risk on households from the magnitude of household response [24][35].

Public transfers are also important to reduce poverty vulnerability. Imbalances are the main cause of poverty in developing countries. The pattern of contemporary economic development often results in a "core-edge" outcome, i.e. the economic development of the central region comes at the expense of the loss of the interests of the marginal area, the faster the development of the central area, the more severe the repression of the marginal area. As a result, families in marginal areas are more vulnerable to poverty [36]. And public transfer payments from developed cities to backward rural areas are meaningful in reducing the vulnerability of poverty [37]. While the above literature confirms the effectiveness of public transfer payments in improving poverty vulnerability, on the other hand, what we need to consider in our practical studies is the efficiency of merit transfer payments in targeting policy beneficiaries in reducing vulnerability objectives, and the effect of public political transfer payments can be effectively enhanced by examining the welfare status of policy beneficiaries and the different levels of demand for public services. Theoretically, different needs for improving poverty vulnerability are closely related to demand income elasticity. Therefore, it is of great practical significance to evaluate scientifically and study the poverty vulnerability of the beneficiaries of public transfer payment improvement policies. By using data from Japanese households, Hashimoto \& Heath calculated the income elasticity of educational expenditure of Japanese households [38]. From the current literature search, it is rare in the past literature to assess the vulnerability effect of public transfer payments on poverty from the perspective of demand 
income elasticity. Therefore, this paper will test the effect of public transfer payments on improving poverty vulnerability in rural households in China by using China's micro-survey panel data for 2014, 2016, and 2018 to measure the income elasticity of health care needs and incorporate them into the analysis of the effects of public transfer payments on poverty vulnerability.

\section{Methods \\ Data source}

The data were derived from the national survey of the China Family Panel Studies (CFPS). China Family Panel Studies (CFPS) is nationally representative in China and with a bi- annually longitudinal survey of Chinese communities, families, and individuals conducted in 2010 by the Institute of Social Science Survey (ISSS) of Peking University, China. CFPS is an ongoing annual longitudinal survey of Chinese communities, families, and individuals launched in 2010 (wave 1), followed up in 2012 (wave 2), and 2014 (wave 3), then in 2016(wave 4), and updated in 2018 (wave 5). The year of the study was 2014, 2016, and 2018 respectively. In this study, we selected the CFPS data for 2014, 2016, and 2018 respectively to assess the vulnerability of rural families to health care poverty and study the financial effects for the goal of reducing vulnerability. In the process of our sample selection, families with missing or abnormal important indicators were excluded, and the sample size of effective rural households after processing was 5754, covering a total of 28 provinces and urban areas in China, and the samples were broadly representative.

\section{Main Dependent Variables}

In the research process, the key-dependent variables are first constructed. It contains the Expected Poverty Vulnerability Index for Health Care for Rural Households in 2014, 2016, and 2018, collects variable information based on household income, health care poverty identification, head-of-household identification, etc. from the CFPS Family Economy Module and the Personal Module to estimate the vulnerability to expected poverty by the method of VEP [25].

\section{Main Independent Variable}

We build the key independent variables. It is divided into two parts of variables. The first part is the government public transfer payment (GTP), from the CFPS family economic survey to collect whether the rural household received the public transfer payment and received the amount of public transfer payment. Of these, each survey year for each of the three years is recorded as 1 for households receiving public transfer payments, while other cases are marked as 0 . The second part is the elasticity of demand income for health care $\left(\mathrm{E} \_\mathrm{H}\right)$ and the interaction between public transfer payment and that elasticity $\left(\mathrm{GTP} * \mathrm{E} \_\mathrm{H}\right)$. The family health care expenditure in each of the three years was collected from the CFPS Household Survey, and the income elasticity of rural households' demand for health care was measured by combining the annual household income.

\section{Covariates}

In collecting and using CFPS family-level data, information on property owners was asked from the 2010 household questionnaire that the head of the household was generally referred to as the name or first person to appear on the family property or land certificate. Since 2012, the screening of heads of the household has added a survey of financial managers in the household questionnaire, which found that the person most familiar with all family members and able to answer some of the family finances in the past year was also the head of the household. Because of this, this paper combines the family real estate owners and financial managers to answer the information, 5574 rural households for the identification of the head of household.

Predisposing factors can be characteristics of the head of household including age (over 18 years of age and under 80 years of age), gender (male/female), marital status (with/without a spouse), years of education (under one year- illiterate/1 6 years-primary school level/6 9years-junior school level/ 9 12 years-senior school level/12 16 years- undergraduate level/more than sixteen years-graduate level) [39]. Besides, also include the number of family members and the square of the head of household's age as the control variables of this study to ensure the stability of the regression results. 
Enabling factors can be measured as tangible resources of obtaining health care services, such as household net income, access to health insurance (yes/no) [39]. Among them, the variable of household net income is the key variable applied to the calculation of income elasticity of rural households' demand for health care. And the variable of access to health insurance is applied to the identification of health and medical multi-dimensional poverty in rural families.

Health-need characteristics can be assessed by chronic illness in the last six months (yes/no), bronchitis illness in the last six months (yes/no), asthma illness in the last six months (yes/no), hospitalized for the last 12 months (yes/no), health status by perceived evaluation ( $0 \sim 4$ score-poor or fair/4 7good or excellent) [39]. These are all key variables in measuring whether rural households have multidimensional poverty in health and health care.

\section{Statistical Models}

\section{Multidimensional poverty identification model for health care}

Refer to the A-F method [40], the identification method consists of three steps. The deprivation critical vector of indicator " $\mathrm{n}$ " is determined at the first step, that is $Z_{n}=\left(Z_{1}, Z_{2}, \cdots, Z_{j}\right)^{t}$. It is assumed that $\rho_{m n}^{t}$ is an identification value for a single vector, for any matrix $Y_{\mathrm{i} \times \mathrm{j}}^{\mathrm{T}}$. When $y_{m n}^{t}<Z_{n}$, it indicates that the rural family " $m$ " is recognized as poverty during the t-period, and counted as $\rho_{m n}^{t}=1$, otherwise, counted as $\rho_{m n}^{t}=0$. The second step is to determine the indicator weight vector, that is, $\mathrm{W}_{\mathrm{n}}=\left(\mathrm{w}_{1}\right.$, $\left.\mathrm{w}_{2}, \cdots, \mathrm{w}_{\mathrm{j}}\right)$. The $\mathrm{W}_{\mathrm{n}}$ is the $\mathrm{nth}$ indicator weight, and meet the condition of the equation, that is $\sum_{\mathrm{n}=1}^{\mathrm{j}} \mathrm{w}_{\mathrm{j}}=1$. Then by constructing the equation of the weighted deprivation matrix $\mathrm{C}$, that is, $c_{m}^{t}=$ $\sum_{\mathrm{n}=1}^{\mathrm{j}} \mathrm{w}_{\mathrm{j}} \rho_{m n}^{t}$, and the family " $\mathrm{m}$ " was deprived of the score on all the indicators during the t-period. At the third step, the multidimensional poverty threshold vector " $\mathrm{k}$ " is set, and when the condition is reached, that is, $c_{m}^{t} \geq \mathrm{k}$, the family " $\mathrm{m}$ " is recognized as a multidimensional poor family during the t-period.

The multidimensional dimension of poverty in health and health care selected in this study is obtained by referring to the Multidimensional Poverty Index (MPI) index system conducted by the Oxford Poverty \& Human Development Initiative (OPHI) in the UK and based on the context of China's actual development [41]. Therefore, based on reference to MPI indicators, the family members in the past six months whether there are chronic illness, bronchitis illness, asthma illness, hospitalization, and selfreported health status as a measure of rural family health deprivation indicators, and in the past year whether family members have participated in medical insurance as an indicator to measure rural family medical deprivation, to build in line with the current reality of China's rural family health and medical multidimensional poverty dimension, indicators, deprivation threshold, and weight (see Table 1).

Table 1 Multidimensional Poverty Indicator System for Health Care

\begin{tabular}{|c|c|c|c|}
\hline Dimensions & Indicators & Threshold of deprivation & Weight \\
\hline \multirow{2}{*}{ Enabling } & health insurance & $\begin{array}{c}\text { Access to the health } \\
\text { insurance(Yes=1, No=0) }\end{array}$ & $1 / 6$ \\
\cline { 2 - 4 } & Chronic illness & $\begin{array}{c}\text { Whether or not chronic } \\
\text { illness has been in the last } \\
\text { six months(Yes=1, No=0) }\end{array}$ & $1 / 6$ \\
\cline { 2 - 4 } Health need & Bronchitis illness & $\begin{array}{c}\text { Whether or not bronchitis } \\
\text { illness has been in the last } \\
\text { six months(Yes=1, No=0) }\end{array}$ & $1 / 6$ \\
\cline { 2 - 4 } & Asthma illness & $\begin{array}{c}\text { Whether or not asthma } \\
\text { illness has been in the last } \\
\text { six months(Yes=1, No=0) }\end{array}$ & $1 / 6$ \\
\cline { 2 - 4 } & Hospitalization & $\begin{array}{c}\text { Whether or not entering } \\
\text { the hospital in the past 12 } \\
\text { months (Yes=1, No=0) }\end{array}$ & $1 / 6$ \\
\cline { 2 - 4 } & Health status & The health status by self- & $1 / 6$ \\
\cline { 2 - 4 }
\end{tabular}




\begin{tabular}{|c|c|c|c|}
\hline & $\begin{array}{c}\text { reported (range from } \\
0 \sim 7 \text { score, below 4 as poor } \\
\text { and over 4 as good health } \\
\text { level) }\end{array}$ & \\
\hline
\end{tabular}

Source: CFPS 2014,2016 and 2018 based on A-F method and MPI indicators [40][41][42].

\section{Health Care Vulnerability as Expected Poverty Model (VEP)}

In this study, we used the method of correcting selective and endogenous bias to assess the impact of government public transfer payments on the health care poverty of rural families in China. Based on the VEP method [25][30][43], we tried to provide examples where vulnerability is defined as the probability that a rural household will fall into health poverty in the future. The basic principle of VEP is the return of observable variables and impact factors to the per capita health care consumption of the family to obtain the expected health care consumption per capita of the family, and then assume that the expected health care consumption per capita of the family obeys the normal distribution of the number, thus obtaining the probability that the expected health care consumption per capita of the future family is lower than a certain value (usually the poverty line), that is, the probability that the family will fall into poverty in the future. By using Chaudhuri's estimation strategy [25] and the three stages of the method proposed by Amemiya [44], and it can be feasible generalized least squared (FGLS), the vulnerability of health poverty can be estimated through three stages. The first step is to estimate the equation of health care consumption and the equation of residuals. The following variables are adopted, including multidimensional poverty (yes $=1$, no $=0$ ), age, educational year, marital status (married $=1$, unmarried $=0$ ), family size, etc., and to control the fixed effect between regions, we also analyze the regional variables represented by dumb variables. The second step uses the fitted value obtained in the first step to build the weight for FGLS estimation. The third step is to select the poverty line, by setting the $\$ 1.90$ and $\$ 3.20$ poverty lines according to the international poverty line standard and combines the exchange rate to achieve the new international poverty line measured in Chinese currency (about RMB 2900 and 5000 ). It is worth noting that in vulnerability studies, the threshold determination of vulnerability is subjective and arbitrary, so this paper uses two threshold values of vulnerability for sensitivity analysis: if the predicted probability of per capita log health of individual households is below $50 \%$ of the poverty line as the first threshold for vulnerability, if the predicted probability of a household per capita receiving below $75 \%$ of the poverty line, as the second threshold for vulnerability, also known as high vulnerability.

\section{Multivariate logistic regression model}

Multivariable logistic regression analysis performed with STATA 15.0 was employed to examine government public transfer payment associated with the marginal effect on the vulnerability of health care poverty in rural families in China. Two series of logistic regression analyses were undertaken. In the first series, based on the factor variables as a di-factor, the factor is the vulnerability of health care expectation poverty (poverty vulnerability $=1$, non-poverty vulnerability $=0$ ). The multi-logistic regression model is selected to study the effect of series one: public transfer payment on the poverty vulnerability of health care in rural China under the condition of controlling the specific characteristics of the head of household. In the second series, the weighted value of household income elasticity to health care demand is measured as the key argument of series two, and the interaction between income elasticity of health care demand and government public transfer payment is constructed. It is incorporated into the logical model of phrase one to examine whether the improved marginal effect of the public transfer payment on the vulnerability of health care poverty in rural families in China is related to the degree of subjective demand for health care in the families, and to make empirical analysis.

\section{Results}

The measurement analysis of the vulnerability of health care poverty

Based on panel data for 2014, 2016, and 2018, we estimate the results of healthy poverty vulnerability based on the $\$ 1.9$ and $\$ 3.2$ the two standard poverty lines [45]. We set a threshold of 
vulnerability line based on Pritchett's research result [28]. It is set the predicted probability that per capita health care for individual households is below $50 \%$ of the poverty line as the expected vulnerability for health care.

Table 2 Compare the vulnerability and incidence of health care poverty in 2014, 2016, and 2018

\begin{tabular}{|c|c|c|c|c|c|c|}
\hline Main statistics & \multicolumn{2}{|c|}{ The Year 2014 } & \multicolumn{2}{|c|}{ The Year of 2016 } & \multicolumn{2}{|c|}{ The Year of 2018 } \\
\hline $\begin{array}{c}\text { Multidimensional poverty } \\
\text { rate }(k \%)\end{array}$ & $k=30 \%$ & $k=40 \%$ & $k=30 \%$ & $k=40 \%$ & $k=30 \%$ & $k=40 \%$ \\
\hline $\begin{array}{c}\text { Incidence of } \\
\text { multidimensional poverty } \\
\text { in health care }\left(R^{c}\right)\end{array}$ & $38.62 \%$ & $9.85 \%$ & $40.32 \%$ & $11.66 \%$ & $44.27 \%$ & $17.60 \%$ \\
\hline $\begin{array}{c}\text { Health care experts } \\
\text { poverty vulnerability } \\
\text { (Poverty line=\$1.9, } \\
k=30 \%)\end{array}$ & \multicolumn{2}{|c|}{$93.08 \%$} & $92.09 \%$ & $50.78 \%$ \\
\hline $\begin{array}{c}\text { Health care experts } \\
\text { poverty vulnerability } \\
\text { (Poverty line=\$3.2, } \\
k=30 \%)\end{array}$ & $96.28 \%$ & $96.02 \%$ & $57.13 \%$ \\
\hline
\end{tabular}

Data source: Authors' own calculation using CFPS 2014, 2016 and 2018 [42].

Note: The incidence of multidimensional poverty $\mathrm{R}^{\mathrm{c}}$ indicates the proportion of poor households $\left(f_{\mathrm{m}}^{\mathrm{c}}\right)$ in the year understudy to the total sample size of households(i), and the formula is: $R^{c}=\frac{\sum_{m=1}^{i} \delta_{m}(k, \gamma)}{i}=\frac{f_{m}^{c}}{i}$.

As can be seen from Table 2, the incidence of multidimensional poverty, as measured by health and medical deprivation $R^{c}$, is on the rise ( $\mathrm{k}=30 \%$, from 38.62 to $44.27 \%$, and $\mathrm{k}=40 \%$, from 9.85 to $17.60 \%$ ), and it is clear that, with the development of the economy and society, the main contributors to poverty have gradually shifted from the demand for basic living to the level of different needs for health and medical care, with the development of the economy and society and the continuous improvement of the quality of family life and living standards. Health and medical care have an important impact on the incidence of multidimensional poverty throughout the study period, and how to meet the different needs of rural families for health and medical care on a larger scale has become a key issue for China to consolidate the achievements of poverty eradication and promote the vigorous development of rural areas. Since the values of the poverty vulnerability indicators for 2014, 2016, and 2018 are influenced by factors other than age, gender, marital status, and length of education in addition to multidimensional poverty, the poverty rate is not much different from the estimated poverty vulnerability values of $30 \%$ or $40 \%$. Therefore, we have selected a poverty rate of 30 percent to measure poverty vulnerability.

And the vulnerability of China to health care poverty has been declining year by year in all three study years, and the gap between poverty vulnerability and the incidence of multidimensional poverty ( $\mathrm{k}=30 \%)$ is narrowing year by year, especially in 2018, when the incidence of multidimensional poverty in health care for rural households in China is $44.27 \%$, and the vulnerability to health care is $50.78 \%$ and $57.13 \%$, respectively, a difference of $6.51 \%$ and $12.86 \%$.

Table 3 Classification of the high, medium, and low vulnerability provinces or cities in 2018 survey wave

\begin{tabular}{|c|c|c|c|}
\hline Class & $\begin{array}{c}\text { Range of } \\
\text { vulnerability } \\
\text { (Average Value) }\end{array}$ & $\begin{array}{l}\text { Provinces or Cites of VEP } \\
\quad \text { (Poverty line=\$1.9) }\end{array}$ & $\begin{array}{l}\text { Provinces or Cites of VEP } \\
\quad \text { (Poverty line=\$3.2) }\end{array}$ \\
\hline High vulnerability & $60 \% \sim 70 \%$ & $\begin{array}{l}\text { Beijing, Shanghai, } \\
\text { Zhejiang, Jiangsu, } \\
\text { Hainan }\end{array}$ & $\begin{array}{c}\text { Beijing, Shanghai, } \\
\text { Zhejiang, Guangdong, } \\
\text { Jiangsu, Hainan, } \\
\text { Heilongjiang, Chongqing, } \\
\text { Hunan, Yunan, } \\
\text { Shandong, Hebei }\end{array}$ \\
\hline
\end{tabular}




\begin{tabular}{|c|c|c|c|}
\hline Moderate vulnerability & $50 \% \sim 60 \%$ & $\begin{array}{c}\text { Guangdong, Heilongjiang, } \\
\text { Chongqing, Hunan, } \\
\text { Yunan, Fujian, } \\
\text { Shandong, Hebei, } \\
\text { Anhui, Shanxi, } \\
\text { Liaolin } \\
\end{array}$ & $\begin{array}{l}\text { Fujian, Henan, } \\
\text { Hubei, Jiangxi, } \\
\text { Anhui, Guizhou, } \\
\text { Shanxi, Sichuan, } \\
\text { Gansu, Liaolin }\end{array}$ \\
\hline Low vulnerability & Below $50 \%$ & $\begin{array}{c}\text { Henan, Tianjin, Hubei, } \\
\text { Jiangxi, Guangxi, } \\
\text { Guizhou, Sichuan, } \\
\text { Xinjiang, Tibet, Gansu, Jilin }\end{array}$ & $\begin{array}{c}\text { Tianjin, Guangxi, } \\
\text { Xinjiang, Tibet, } \\
\text { Jilin }\end{array}$ \\
\hline
\end{tabular}

Source: VEP estimation method using CFPS 2018 [25][28][29][30][42].

Regional poverty disparities are common in many developing economies especially pronounced in some such as China. In China, for example, counties classified as national or provincially poor (assessed according to poverty level) selectively receive additional government financial support [25]. It is very noteworthy that in some provinces or cities with high rates of poverty, the incidence of poverty is much higher than the national poverty standard. However, the estimated incidence of poverty vulnerability in these areas with high incidences of poverty may be well below the national poverty vulnerability criteria [25]. Table 3 reflects the incidence of poverty vulnerability in China's rural geography at the $\$ 1.9$ and $\$ 3.2$ vulnerability criteria based on 2018 CFPS's data. As can be seen from Table 3, China is classified as a poor Yunnan, Tibet, and other regions, and in this study to calculate the average incidence of multidimensional poverty in health care, Yunnan and Tibet have a poverty incidence rate of well above $60 \%$, indicating a high incidence of poverty. However, the expected poverty vulnerability assessed under the \$1.9 and \$3.2 vulnerability criteria in the two regions were divided into low vulnerabilities to health care. Similarly, cities with low incidences of poverty, such as Beijing and Shanghai, are classified as highly poor vulnerabilities to health care, as assessed in the \$1.9 and \$3.2 vulnerability criteria. This may be because in rural areas with high poverty rates, such as Yunnan and Tibet, the level of economic development and population mobility are relatively low, with most families relying mainly on government financial assistance to support their survival and development, while family members have low opportunities to work outside the home for long periods. Then, family members have a lower risk of chronic and bronchitis illnesses. As a result, the incidence of rural family health care poverty vulnerability is low in these areas. Conversely, Beijing and Shanghai are the political and economic centers of China, respectively, and the two cities have high levels of economic development and high mobility [46]. Rural families in these areas receive less government financial assistance and are more likely to be employed in neighboring or towns, which encourages rural family members to go out to work. In addition to these areas, high population concentration can easily lead to environmental pollution caused by smoking. Combined with these circumstances, it is easy to judge that rural families in these areas have a higher probability of chronic illness, bronchitis, and other illnesses, and may assess the high vulnerability of health care poverty in Beijing and Shanghai.

\section{Multivariate Logistic Regression}

Table 4 lists the descriptive statistics of the effect of public transfer payments on vulnerability to health care poverty in Chinese rural households.

Table 4 Descriptive statistics for variables

\begin{tabular}{|c|c|c|c|c|c|c|c|c|c|}
\hline Variables & Year & $\begin{array}{c}\text { VEP_1 } \\
\text { (Poverty } \\
\text { line=\$1.9) }\end{array}$ & $\begin{array}{c}\text { VEP_2 } \\
\text { (poverty } \\
\text { line=\$3.2) }\end{array}$ & $\begin{array}{c}\text { (GTP) } \\
\text { (Receiv } \\
\text { ed=1, }\end{array}$ & Age & $\operatorname{Age}^{2}$ & $\begin{array}{c}\text { Gender } \\
\text { (Male= } \\
1,\end{array}$ & $\begin{array}{c}\text { Educatio } \\
\text { nal } \\
\text { Year }\end{array}$ & $\begin{array}{c}\text { Family } \\
\text { Size } \\
\left(F_{-}\right.\end{array}$ \\
\hline
\end{tabular}




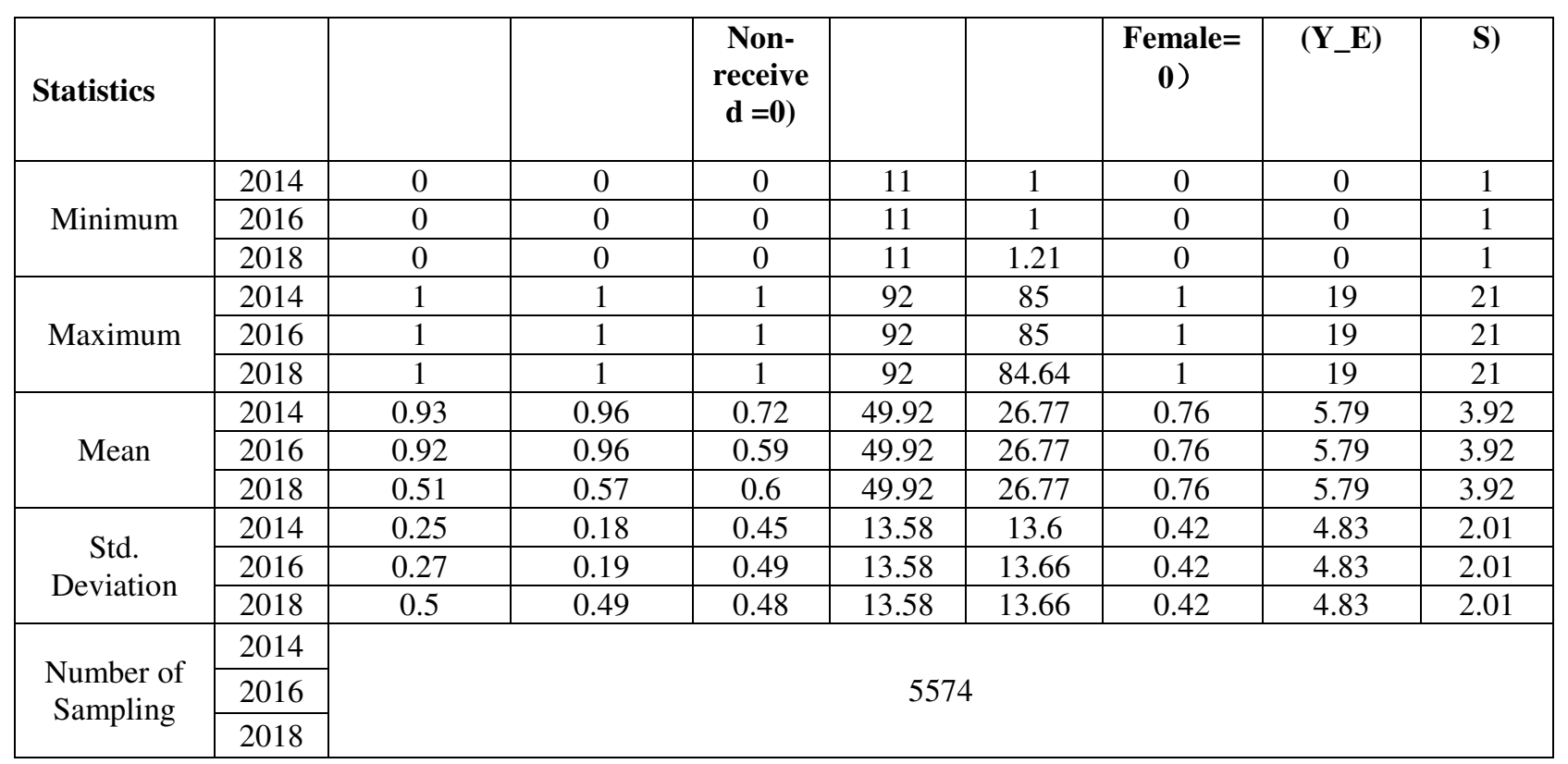

Source: CFPS 2014, 2016 and 2018[42].

\section{Series one model: multi-variables logistic model effect analysis}

Series one is a study of the marginal effect of government public transfer payment on the vulnerability of health and hygiene poverty in rural families. Based on the particularity of the Logistic model, the contribution rate of fiscal transfer payment to vulnerable poverty is understood more directly, so this paper translates the regression result into marginal effect. As can be seen from the marginal effects regression results in Table 5, although only 71.84 percent, $59.96 \%$, and $60.03 \%$ of all sample households were transferred in 2014, 2016, and 2018 respectively, in response to China's actual development, the overall level of rural economic development in China was low in 2014 and 2016, with local governments paying far more to cities than in rural areas due to regional political and economic tournaments. As a result, the scope of the Chinese government's subsidies to rural families is mainly concentrated in agricultural subsidies and limited strength, in these two study years, the proportion of rural families in line with health care vulnerability to poverty than the proportion of families receiving public transfer payments. Besides, local governments fail to take into account the level of demand for health care in rural households, resulting in a serious underpayment of transfers in this area, which is why government public transfer payments, whether set at $\$ 1.9$ or $\$ 3.2$ in 2014 and in 2016 , have little impact on health care vulnerability in rural areas [47]. In 2018, the government's fiscal transfer payments contributed to a decline in rural household health care vulnerability to poverty, while when the poverty line was set at $\$ 1.9$ and $\$ 3.2$, the vulnerability of rural households that received public transfer payments in 2018 fell by $3.4 \%$ and $6.04 \%$, respectively. This may be because the proportion of poor households that meet the vulnerability of health care will be smaller in 2018 than the proportion receiving public transfer payments. From the control variables, it can be found from the control variables that, during 2014, 2016, and 2018 year surveys, empirical results found that female-headed households with younger age and a higher level of education were more responsive to reducing the vulnerability of health care through public transfer payments [48]. And vulnerability to poverty was found to be higher among small-scale rural households than in large-scale rural households during the 2014 and 2016 year surveys, but this result was not valid in 2018, and in 2018 large-scale rural households were found to be more responsive to public transfer payments reducing the vulnerability of health care. This may be because with the economic development level of various regions of China has increased significantly recently, the larger the number of families, the greater their ability to jointly fight the risks of future health care, and also related to the three-year 
study year of health care vulnerable poor families accounted for a different proportion of the overall rural household sample.

We can see that during the three expeditions in 2016, 2014, and 2018, the targeting mechanism for poverty demand for health care vulnerability due to public transfer payments was inadequate. Government public transfer payments have contributed only to the decline in poverty in rural family health care vulnerability. This may be because members of the family have different levels of demand for health care, and government transfer payments do not change accordingly to the subjective needs of the family, and therefore may lead to transfer payments that are less effective in alleviating the vulnerability of health care poverty [49]. To further measure the effectiveness of public transfer payment on rural family health care vulnerability to poverty, the income elasticity of rural households' health care needs is analyzed in the empirical evidence of series two and incorporated into the same model.

Table 5 Logistic regression results on the vulnerability effect of fiscal transfer payments on rural family health care poverty

\begin{tabular}{|c|c|c|c|c|c|c|}
\hline \multirow{2}{*}{ Variables } & \multicolumn{3}{|c|}{$\begin{array}{c}\text { VEP_1 } \\
\text { (Poverty line=\$1.9) }\end{array}$} & \multicolumn{3}{|c|}{$\begin{array}{c}\text { VEP_2 } \\
\text { (poverty line=\$3.2) }\end{array}$} \\
\hline & 2014 & 2016 & 2018 & 2014 & 2016 & 2018 \\
\hline \multirow{2}{*}{ Statisitics } & Coefficient & Coefficient & Coefficient & Coefficient & Coefficient & Coefficient \\
\hline & $\mathrm{P}>|\mathrm{z}|$ & $\mathrm{P}>|\mathrm{z}|$ & $\mathrm{P}>|\mathrm{z}|$ & $\mathrm{P}>|\mathrm{z}|$ & $\mathrm{P}>|\mathrm{z}|$ & $\mathrm{P}>|\mathrm{z}|$ \\
\hline GTP & $\begin{array}{r}-0.0105 \\
(0.139)\end{array}$ & $\begin{array}{l}-0.0015 \\
(0.831)\end{array}$ & $\begin{array}{c}-0.0340^{* * * *} \\
(0.010)\end{array}$ & $\begin{array}{l}-0.0031 \\
(0.157)\end{array}$ & $\begin{array}{l}-0.0048 \\
(0.354)\end{array}$ & $\begin{array}{c}-0.0604^{* * * *} \\
(0.000)\end{array}$ \\
\hline Age & $\begin{array}{l}0.0014 \\
(0.257)\end{array}$ & $\begin{array}{l}0.0019 \\
(0.151)\end{array}$ & $\begin{array}{l}0.0044^{*} \\
(0.099)\end{array}$ & $\begin{array}{l}0.0002 \\
(0.788)\end{array}$ & $\begin{array}{l}0.0006 \\
(0.560)\end{array}$ & $\begin{array}{c}0.0002 \\
(0.925)\end{array}$ \\
\hline $\mathrm{Age}^{2}$ & $\begin{array}{l}0.0016 \\
(0.187)\end{array}$ & $\begin{array}{l}0.0024^{*} \\
(0.066)\end{array}$ & $\begin{array}{l}0.0016^{* *} \\
(0.045)\end{array}$ & $\begin{array}{l}0.0003 \\
(0.739)\end{array}$ & $\begin{array}{l}0.0002 \\
(0.762)\end{array}$ & $\begin{array}{l}0.0044^{*} \\
(0.087)\end{array}$ \\
\hline Gender & $\begin{array}{c}0.0221^{* * *} \\
(0.004)\end{array}$ & $\begin{array}{c}0.0232^{* * * *} \\
(0.005)\end{array}$ & $\begin{array}{c}-0.1028^{* * *} \\
(0.000)\end{array}$ & $\begin{array}{c}0.0149^{* * * *} \\
(0.008)\end{array}$ & $\begin{array}{c}0.0178^{* * * *} \\
(0.002)\end{array}$ & $\begin{array}{c}0.0799^{* * *} \\
(0.000)\end{array}$ \\
\hline Y_E & $\begin{array}{l}-0.0009 \\
(0.181)\end{array}$ & $\begin{array}{l}-0.0005 \\
(0.502)\end{array}$ & $\begin{array}{c}-0.0113^{* * *} \\
(0.000)\end{array}$ & $\begin{array}{c}-0.00003 \\
(0.949)\end{array}$ & $\begin{array}{c}-0.0014^{* *} \\
(0.016)\end{array}$ & $\begin{array}{c}-0.0122^{* * *} \\
(0.000)\end{array}$ \\
\hline F_S & $\begin{array}{l}0.021^{* * * *} \\
(0.000)\end{array}$ & $\begin{array}{l}0.0131^{* * *} \\
(0.000)\end{array}$ & $\begin{array}{c}-0.0152^{* * *} \\
(0.000)\end{array}$ & $\begin{array}{l}0.0153^{* * * *} \\
(0.000)\end{array}$ & $\begin{array}{l}0.0131^{* * *} \\
(0.000)\end{array}$ & $\begin{array}{c}-0.0457^{* * *} \\
(0.000)\end{array}$ \\
\hline $\begin{array}{c}\text { Log } \\
\text { likelihood }\end{array}$ & -1352.12 & -1514.91 & -3909.70 & -843.12 & -891.95 & -3688.69 \\
\hline $\begin{array}{c}\text { LR } \\
\text { Statistics }\end{array}$ & 189.85 & 152.19 & 155.91 & 142.54 & 141.43 & 482.09 \\
\hline $\begin{array}{l}\text { Number of } \\
\text { Sampling }\end{array}$ & 5754 & 5754 & 5754 & 5754 & 5754 & 5754 \\
\hline
\end{tabular}

Source: CFPS 2014, 2016 and 2018[42].

Note: $* * * * * *$ represented statistic indicators significantly at $10 \%, 5 \%$, and $1 \%$, respectively.

\section{Series two model: multi-variables logistic model effect analysis}

At the first step, define the income elasticity of demand for public services. "Income Elasticity of Demand" refers to the extent to which changes in consumers' income affect changes in demand for a commodity, or how changes in demand for a commodity react to changes in consumer income over some time, subject to the same conditions. "Income Elasticity of Demand on Public Goods," can be expressed as the extent to which changes in consumer income in public services affect changes in demand for public goods over a while, subject to other conditions. This paper mainly studies the income elasticity (E_H) of rural households' demand for health, and the demand for public services is the demand for public services that consumers are willing and able to pay, that is, the demand for available currency under the constraints of each household budget [38]. Thus, the money that rural households pay for healthy public 
services is the demand for health public services. According to the annual household health expenditure obtained from the family economy module of the CFPS database, the demand for the health of rural households is obtained, and the annual income of rural households is in the amount of income of consumers who consume such goods. In the second step, estimate the income elasticity of demand for public goods. To study the demand relationship between rural household income and health public service, this paper constructs a double-to-scale model, taking the natural icing of rural household income as the key argument, and the natural icing on the demand for health care as the dependent variable, establishing the general regression equation and obtaining the argument coefficient, to measure the income elasticity of the family's demand for health care. At the third step, do the empirical test of interaction effects. Before analyzing the interaction between the two variables of income elasticity and public transfer payment of health care demand on the poverty effect of rural family health care, it is necessary to line-check whether the variables composed of interactive items have an interaction effect and to test whether the interactions in the two models of $\$ 1.9$ and $\$ 3.20$ in poor counties are significantly combined, i.e. to test the original hypothesis that the coefficient of the interaction items is all 0 . It can be seen that the interaction item is the interaction effect between the family's income elasticity and the public transfer payment for health care needs (GTP*E_H).

As can be seen from the test results of Table 6 , in the models of the poverty line of $\$ 1.9$ and $\$ 3.2$, the Prob. value of the interactive item introduced by GTP*E_H is less than chi2, and both are significantly significant at the confidence level of 0.1 , rejecting the assumption that the coefficient of the interaction term is all 0. It is indicated that the joint significance test of this interaction item has passed [50]. As derived from Table 6, the Logistic model estimates that the marginal effect of fiscal transfer payments on rural household health vulnerability to poverty is effective.

Table 6 The interaction effect of the joint variable

\begin{tabular}{|c|c|c|}
\hline Variables & $\begin{array}{c}\text { GTP*E_H } \\
\text { (VEP_1) }\end{array}$ & $\begin{array}{c}\text { GTP*E_H } \\
(\text { VEP_2) }\end{array}$ \\
\hline Wald (Prob.) & $0.0000^{* * *}$ & $0.0000^{* * * *}$ \\
\hline Chi2 (1) & 261.61 & 173.17 \\
\hline
\end{tabular}

Source: CFPS 2014, 2016 and 2018[42].

Note: $* * * * * *$ represented statistic indicators significantly at $10 \%, 5 \%$, and $1 \%$, respectively.

From the return results of Table 7, it can be seen that in the 2014, 2016, and 2018 survey waves, there was a significant positive correlation between the income elasticity of rural households' demand for health care and the decrease in rural family health care vulnerability, indicating that the greater the elasticity of rural families' demand for health care, which means that these families' constant pursuit of health levels drives them to respond to future health and medical risks so that these families are more able to cope with negative impact risks and deal with risks, and the lower the probability of suffering from health care vulnerability to poverty in the future. Besides, after adding the income elasticity variable of rural households' demand for health care in the three study years, the interaction between demand income elasticity and public transfer payment showed a significant positive relationship with the decline of rural family health care vulnerability. From the regression coefficient values, the marginal utility of the interactions in 2014, 2016, and 2018 to improve the vulnerability of rural household health care to poverty risk at $\$ 1.90$ is $0.0258,0.5279$, and 0.1981 respectively, and the marginal utility of poverty risk to improving the vulnerability of rural family health care at $\$ 3.20$ is $0.0124,0.3205$, and 0.2283 respectively. In 2014 and 2016, as households' demand for health care increased, the effect of public transfer payments on improving their vulnerability changed significantly from the inability to incorporate demand income elasticity into the significant effect of inclusion in the elasticity to improve their vulnerability. In 2018, the effect of fiscal transfers on improving their vulnerability will increase when they are not included in 
demand income elasticity. It means that the local government's public transfer payment means to enhance the targeting mechanism of the poverty demand of health care vulnerability, the demand of rural families for health care is increasing year by year, and the proportion of its members in sub-health states and suffering from chronic diseases is increasing year by year, which means that the actual cost and opportunity cost of health care will continue to increase, and if more attention is paid to the degree of rural families' demand for health care, it will help rural families to improve their ability to cope with the risk of health care. Therefore, fiscal transfer payments have significant positive effects on improving the vulnerability of health care to poverty [51].

Table 7 Marginal Logistic regression results of the poverty effect of the fiscal transfer payment on rural family health care vulnerability

\begin{tabular}{|c|c|c|c|c|c|c|}
\hline \multirow{2}{*}{ Variables } & \multicolumn{3}{|c|}{$\begin{array}{c}\text { VEP_1 } \\
(\text { Poverty line=\$1.9) }\end{array}$} & \multicolumn{3}{|c|}{$\begin{array}{c}\text { VEP_2 } \\
\text { (poverty line=\$3.2) }\end{array}$} \\
\hline & 2014 & 2016 & 2018 & 2014 & 2016 & 2018 \\
\hline E_H & $\begin{array}{c}-0.0281^{* * *} \\
(0.000)\end{array}$ & $\begin{array}{l}-.02196^{* * *} \\
(0.000)\end{array}$ & $\begin{array}{c}-0.0791^{* * * *} \\
(0.000)\end{array}$ & $\begin{array}{c}-0.0174^{* * * *} \\
(0.000)\end{array}$ & $\begin{array}{c}-0.0512^{* * *} \\
(0.000)\end{array}$ & $\begin{array}{c}-0.0925^{* * *} \\
(0.000)\end{array}$ \\
\hline GTP*E_H & $\begin{array}{l}-0.0258^{* * *} \\
(0.000)\end{array}$ & $\begin{array}{c}-0.5279^{* * *} \\
(0.000)\end{array}$ & $\begin{array}{c}-0.1981^{* * *} \\
(0.000)\end{array}$ & $\begin{array}{c}-0.0124^{* * *} \\
(0.009)\end{array}$ & $\begin{array}{c}-0.3205^{* * * *} \\
(0.000)\end{array}$ & $\begin{array}{c}-0.2283^{* * * *} \\
(0.000)\end{array}$ \\
\hline Age & $\begin{array}{l}0.0006 \\
(0.602)\end{array}$ & $\begin{array}{l}0.0009 \\
(0.400)\end{array}$ & $\begin{array}{l}0.0042^{*} \\
(0.100)\end{array}$ & $\begin{array}{l}0.0002 \\
(0.770)\end{array}$ & $\begin{array}{l}0.0007 \\
(0.421)\end{array}$ & $\begin{array}{l}0.0004 \\
(0.856)\end{array}$ \\
\hline $\mathrm{Age}^{2}$ & $\begin{array}{l}0.0009 \\
(0.437)\end{array}$ & $\begin{array}{l}-0.0003 \\
(0.746)\end{array}$ & $\begin{array}{l}-0.0014^{*} \\
(0.588)\end{array}$ & $\begin{array}{l}0.0001 \\
(0.913)\end{array}$ & $\begin{array}{l}0.0009 \\
(0.251)\end{array}$ & $\begin{array}{l}0.0052^{* *} \\
(0.043)\end{array}$ \\
\hline Gender & $\begin{array}{c}0.0217^{* * *} \\
(0.003)\end{array}$ & $\begin{array}{l}0.0075^{*} \\
(0.070)\end{array}$ & $\begin{array}{c}-0.1026^{* * *} \\
(0.000)\end{array}$ & $\begin{array}{c}0.0154^{* * *} \\
(0.005)\end{array}$ & $\begin{array}{c}0.0108^{* *} \\
(0.028)\end{array}$ & $\begin{array}{c}-0.0822^{* * *} \\
(0.000)\end{array}$ \\
\hline Y_E & $\begin{array}{c}-0.0004 \\
(0.511)\end{array}$ & $\begin{array}{c}-0.0015^{* *} \\
(0.026)\end{array}$ & $\begin{array}{c}-0.0096^{* * *} \\
(0.000)\end{array}$ & $\begin{array}{l}-0.00036 \\
(0.514)\end{array}$ & $\begin{array}{l}-0.0005 \\
(0.347)\end{array}$ & $\begin{array}{c}0.0105^{* * *} \\
(0.000)\end{array}$ \\
\hline F_S & $\begin{array}{c}0.0229^{* * * *} \\
(0.000)\end{array}$ & $\begin{array}{l}0.0199^{* * * *} \\
(0.000)\end{array}$ & $\begin{array}{l}-.0133^{* * *} \\
(0.000)\end{array}$ & $\begin{array}{c}0.0158^{* * *} \\
(0.000)\end{array}$ & $\begin{array}{c}0.0136^{* * *} \\
(0.000)\end{array}$ & $\begin{array}{l}-0.0440^{* * *} \\
(0.000)\end{array}$ \\
\hline Loglikelihood & -1288.93 & -1022.16 & -3793.30 & -802.56 & -626.31 & -3524.67 \\
\hline LR Statistics & 316.23 & 1137.70 & 388.73 & 223.67 & 672.69 & 810.15 \\
\hline $\begin{array}{l}\text { Number of } \\
\text { Sampling }\end{array}$ & 5754 & 5754 & 5754 & 5754 & 5754 & 5754 \\
\hline
\end{tabular}

Source: CFPS 2014, 2016 and 2018[42].

Note: $* * * * * *$ represented statistic indicators significantly at $10 \%, 5 \%$, and $1 \%$, respectively.

\section{Cross-validation regression}

To ensure the robustness of the regression results, the paper replaces the poverty rate with the original k-30\% to k-40\% by transforming the interpreted variables and the replacement estimation method and uses the random effect Probit(robust) model to regress the vulnerability to poverty marginal effect of the two models VEP_1 and VEP_2. Table 8 reports the results of the robust test analysis, and the regression results show that the household head characteristic variables are controlled, and after adding the interaction effect between the family's income elasticity to health care needs and the public transfer payment, except for the two control variables of age and age squared in 2014 and 2016, the other key variables are non-significant, namely, the income elasticity of household demand for health care, the interaction effect between family income elasticity of health care needs and public transfer payment, and the gender of the head of household. Education and family size are highly significant at the level of $10 \%$, $5 \%$, and $1 \%$, respectively. And the coefficient symbol of the variable is consistent with the series two Logistic model, and the model has passed the Wald test, which shows that the conclusion of introducing 
the income elasticity of family demand for health and analyzing the poverty effect of the public transfer payment on rural family health care vulnerability is stable and reliable.

Table 8 Marginal Porbit(Robust) regression results of the poverty effect of the fiscal transfer payment on rural family health care vulnerability

\begin{tabular}{|c|c|c|c|c|c|c|}
\hline \multirow{2}{*}{ Variables } & \multicolumn{3}{|c|}{$\begin{array}{c}\text { VEP_1 } \\
(\text { Poverty line=\$1.9) }\end{array}$} & \multicolumn{3}{|c|}{$\begin{array}{c}\text { VEP_2 } \\
\text { (poverty line=\$3.2) }\end{array}$} \\
\hline & 2014 & 2016 & 2018 & 2014 & 2016 & 2018 \\
\hline E_H & $\begin{array}{c}-0.0302^{* * *} \\
(0.000)\end{array}$ & $\begin{array}{c}-0.1371^{* * *} \\
(0.000)\end{array}$ & $\begin{array}{c}-0.1510^{* * *} \\
(0.000)\end{array}$ & $\begin{array}{c}-0.0184^{* * *} \\
(0.000)\end{array}$ & $\begin{array}{c}-0.0578^{* * *} \\
(0.000)\end{array}$ & $\begin{array}{c}-0.1502^{* * *} \\
(0.000)\end{array}$ \\
\hline GTP*E_H & $\begin{array}{c}-0.0356^{* * *} \\
(0.000)\end{array}$ & $\begin{array}{c}-0.5946^{* * *} \\
(0.000)\end{array}$ & $\begin{array}{c}-0.1991^{* * *} \\
(0.000)\end{array}$ & $\begin{array}{c}-0.0183^{* * *} \\
(0.001)\end{array}$ & $\begin{array}{c}-0.3210^{* * *} \\
(0.000)\end{array}$ & $\begin{array}{c}-0.2261^{* * * *} \\
(0.000)\end{array}$ \\
\hline Age & $\begin{array}{l}0.0007 \\
(0.545)\end{array}$ & $\begin{array}{l}0.0013 \\
(0.236)\end{array}$ & $\begin{array}{l}0.0043^{*} \\
(0.097)\end{array}$ & $\begin{array}{l}0.0002 \\
(0.774)\end{array}$ & $\begin{array}{l}0.0005 \\
(0.545)\end{array}$ & $\begin{array}{l}0.0001 \\
(0.977)\end{array}$ \\
\hline $\mathrm{Age}^{2}$ & $\begin{array}{l}0.0010 \\
(0.393)\end{array}$ & $\begin{array}{l}0.0009 \\
(0.384)\end{array}$ & $\begin{array}{l}0.0015^{*} \\
(0.053)\end{array}$ & $\begin{array}{l}0.0001 \\
(0.879)\end{array}$ & $\begin{array}{c}0.000 \\
(0.380)\end{array}$ & $\begin{array}{l}0.0046^{*} \\
(0.068)\end{array}$ \\
\hline Gender & $\begin{array}{c}0.0221^{* * *} \\
(0.003)\end{array}$ & $\begin{array}{c}0.0108^{* * *} \\
(0.113)\end{array}$ & $\begin{array}{c}0.1013^{* * *} \\
(0.000)\end{array}$ & $\begin{array}{c}0.0153^{* * *} \\
(0.005)\end{array}$ & $\begin{array}{c}0.0103^{* *} \\
(0.032)\end{array}$ & $\begin{array}{l}0.0822^{* * *} \\
(0.000)\end{array}$ \\
\hline Y_E & $\begin{array}{l}-0.0005 \\
(0.475)\end{array}$ & $\begin{array}{r}-0.0010 \\
(0.117)\end{array}$ & $\begin{array}{c}-0.0097^{* * * *} \\
(0.000)\end{array}$ & $\begin{array}{l}-0.0004 \\
(0.504)\end{array}$ & $\begin{array}{l}-0.0001 \\
(0.248)\end{array}$ & $\begin{array}{c}-0.0105^{* * *} \\
(0.000)\end{array}$ \\
\hline F_S & $\begin{array}{c}0.0209^{* * * *} \\
(0.000)\end{array}$ & $\begin{array}{c}0.0176^{* * * *} \\
(0.000)\end{array}$ & $\begin{array}{l}-0.0133^{* * *} \\
(0.000)\end{array}$ & $\begin{array}{c}0.0151^{* * * *} \\
(0.000)\end{array}$ & $\begin{array}{c}0.0121^{* * *} \\
(0.000)\end{array}$ & $\begin{array}{c}-0.0438^{* * * *} \\
(0.000)\end{array}$ \\
\hline Loglikelihood & -1282.257 & -1023.15 & -3793.51 & -796.9304 & -611.08 & -3529.13 \\
\hline LR Statistics & 329.57 & 1135.72 & 388.30 & 234.92 & 703.17 & 801.22 \\
\hline $\begin{array}{l}\text { Number of } \\
\text { Sampling }\end{array}$ & 5754 & 5754 & 5754 & 5754 & 5754 & 5754 \\
\hline
\end{tabular}

Source: CFPS 2014, 2016 and 2018 [42].

Note: $* * * * * *$ represented statistic indicators significantly at $10 \%, 5 \%$, and $1 \%$, respectively.

\section{Discussion}

In this paper, our results show that there are obvious differences in the vulnerability of health care poverty among rural families in China. We estimate the vulnerability of rural households in China to multidimensional poverty and poverty in health care in 2014, 2016, and 2018 survey wave, respectively, and compared the vulnerability of 5,574 rural households to health care poverty in 28 provinces and cities in the 2018 survey wave. Based on the importance of spatial geographical distribution, we divide the data from 28 provinces and cities into the eastern, central, western and northeastern regions of China to examine the vulnerability of rural family health care poverty in four regions of China (see Fig. 1). We find that when the poverty line standard is $\$ 1.90$ or $\$ 3.2$, the expected measure of rural family health care poverty vulnerability is the lowest in western China, followed by the central region, and the highest poverty vulnerability index is China's highest level of economic development and low-income poverty in the eastern region. This finding is consistent with the findings of [25]. Although Chaudhuri 's study measured the incidence of income poverty and the vulnerability of income poverty from an income poverty perspective, while this paper measured the incidence of multidimensional poverty and the vulnerability of health care poverty in rural households. From Chaudhuri 's research, it has shown that areas with high incidences of poverty may experience lower levels of expected poverty vulnerability because of the direct correlation between the incidence of poverty and local levels of socio-economic development and government fiscal policies, while the expected vulnerability of poverty is based on the current study subjects' situation, population mobility, etc. 


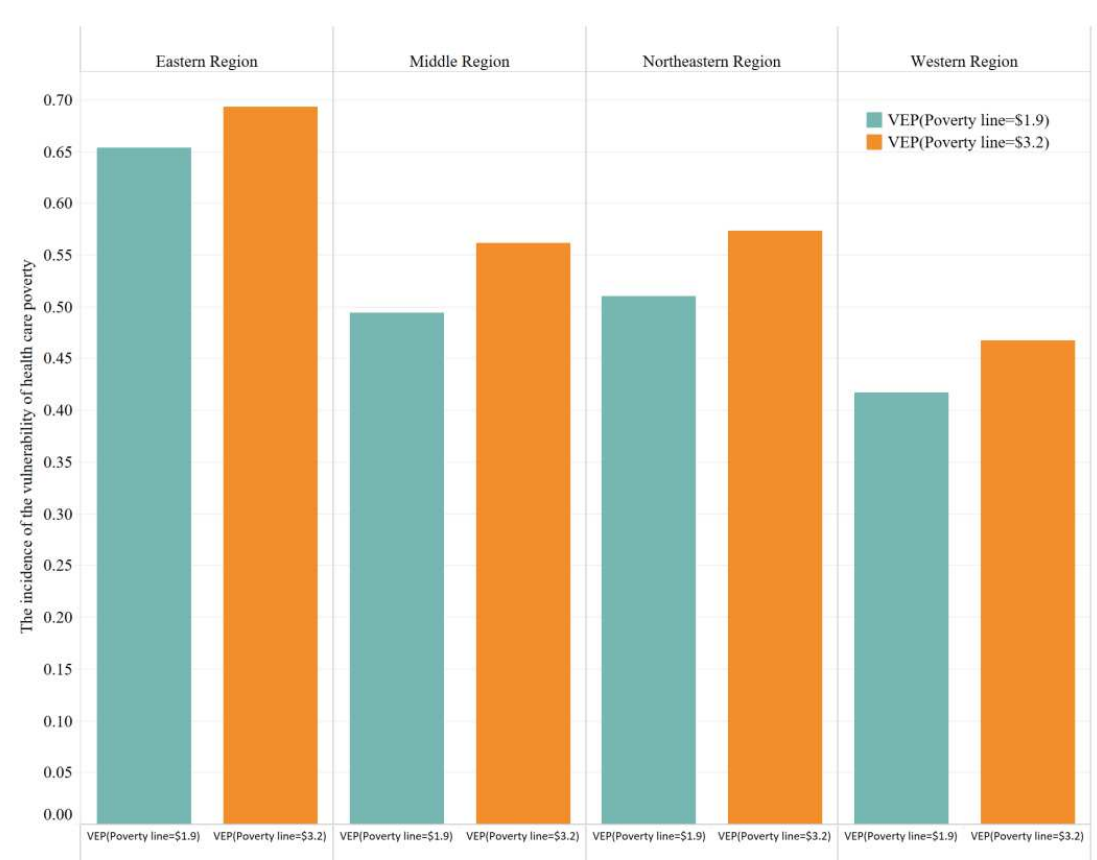

Fig.1 The incidence of the vulnerability of health care poverty is shown in the eastern, middle, western, northeastern and western regions of China (there are 28 provinces and cities in total due to the difficulty of data acquisition in other provinces which divides all provinces in China into four regions: east, middle, northeast, and west) [52].

From the return of the effect of public transfer payments on the health care vulnerability of rural families in China, it can be seen that government public transfer payments have had little effect on improving the vulnerability of rural family health care in 2014, 2016, and 2018 survey wave. This shows that the proportion of public transfer payments made by local governments to rural areas falls far short of the proportion of rural households that are expected to be vulnerable to health care. More importantly, it also explains the serious lack of public policy targeting by local governments, whose allocation of public transfers to rural households does not take into account the extent and differences in the needs of rural households for health care. Thus, it brings about the invalidation effect of public transfer payments.

When compared to the previous studies, similar conclusions are drawn that predisposing factors are also the obvious factors the effect of public transfer payments on the vulnerability of health care to poverty. We show that the head of rural households for the younger and more educated female characteristics, government public transfer payments have been more effective than other situations in improving their vulnerability to health care poverty [53], [48]. However, our study applying income elasticity from rural households' demand for health care into the multi-variables logistic regression model extended the findings. We find that rural households have greater income elasticity in their demand for health care, indicating that there may be a potential chronic risk or other potential health risks, resulting in a much greater demand for health care than they can afford to spend on it [54], [55]. Moreover, we show that the interaction between the elasticity of income elasticity of rural households' demand for health care and the government's public transfer payment has a significant effect on improving the vulnerability of rural families to health care poverty. It is suggesting that if the Government is aware of the differences in the demand for health care between different rural households, it should develop specific public mechanisms to target them. The effect of government public transfer payments on improving the vulnerability of rural families to health care poverty will then be efficient. These findings show novelty and difference in terms of the effects of public transfer payments on improving poverty vulnerability, in contrast to previous studies [25], [30]. 


\section{Conclusions}

In conclusion, we used data from the China Family Panel Studies (CFPS) in 2016, 2014, and 2018 survey waves to prove the effect of government public transfer payments on the vulnerability of rural families to health care poverty in China. By estimating and comparing the incidence of health care multidimensional poverty and expected poverty vulnerability of rural families in China in three study years, it is found that the incidence of expected poverty vulnerability in the three study years is much higher than that of multidimensional poverty. Further, we classify the rural family health care poverty vulnerability in various provinces and cities in China. It is showed that the vulnerability of health care poverty is higher in areas with high economic development than in areas with low economic development. This situation may be closely related to the opportunities, intensity of work of members of rural households, public transfer payment support, and population mobility in the region.

We used two series of multi-variables logistics models to regress the marginal effects of public transfer payment to the vulnerability of rural family health care poverty. Series one of model results show that the government public transfer payment has little effect on improving the vulnerability of rural family health care poverty, the reason is that the public transfer payment input is less than the proportion of poverty vulnerability and the lack of public transfer payment targeting mechanism. Then through the series two models to make up for the imperfect public transfer payment targeting mechanism. Series two model includes the indicators of income elasticity of rural families' health care needs and incorporates the income elasticity index of health care needs and the interaction between public transfer payments and their elasticity into the logistic model for regression analysis. The results show that the income elasticity of health care demand and the interaction between public transfer payments and their elasticity have significant effects on improving the vulnerability of rural family health care poverty. Our analysis emphasizes the importance of government departments in improving the targeting of public transfer payments to reduce the vulnerability of health care poverty in rural households.

\section{Abbreviations}

CFPS: China Family Panel Studies; ISSS: Institute of Social Science Survey; A-F: Alkire-Foster; MPI: Multidimensional Poverty Index; OPHI: Oxford Poverty \& Human Development Initiative

\section{Acknowledgments}

The work was financially supported by Jiangxi Normal University. The author appreciates the Institute of Social Survey at Peking University for granting access to the data of 2014, 2016 and 2018 China Family Panel Studies. The author greatly thanks NCSU for the valuable opportunity to learn and appreciates the anonymous reviewers for their valuable comments on an earlier draft of our paper.

\section{Declarations}

\section{Ethics approval and consent to participate}

This study adhered to the tenets of the Declaration of Helsinki and was approved by the Ethics Committee of Jiangxi Normal University. This is an analysis of secondary data so ethics approval is not required. And all participants provided written informed consent to participate. The confidentiality and privacy of all personal information were secured.

\section{Consent for publication}

"Not applicable"

\section{Competing interests}

The authors declare that they have no competing interests 


\section{Authors' contributions}

Y.L. conceived the idea and participated in the statistical analysis and interpretation of the results. Y.L. drafted and reviewed the manuscript. All authors read and approved the final manuscript.

\section{Author details}

${ }^{1}$ School of Finance, Jiangxi Normal University, Nanchang, 330013 China. ${ }^{2}$ North Carolina State University, P. O. Box 8005, Raleigh, NC 27695-8005 USA

\section{References Cited:}

[1] "National Bureau of Statistics of China," China Statistical Yearbok 2020, 2020. .

[2] D. H. Perkins, "The Chinese Economy: Transitions and Growth - By Barry Naughton," Dev. Econ., vol. 46, no. 3, pp. 315-317, Sep. 2008, doi: https://doi.org/10.1111/j.1746-1049.2008.068_1.x.

[3] R. Warshaw, "Health Disparities Affect Millions in Rural U.S. Communities," 2017. https://www.aamc.org/news-insights/health-disparities-affect-millions-rural-us-communities (accessed Mar. 30, 2021).

[4] M. Ravallion and J. Jalan, "Transient Poverty in Rural China," World Bank Policy Res. Work. Pap., vol. 357, no. 1616, pp. 338-357, 1996.

[5] P. J. Dobriansky, R. M. Suzman, and R. J. Hodes, "Why Population Aging Matters - A Global Perspective," US Dep. State, pp. 1-32, 2007, [Online]. Available: papers2://publication/uuid/4B8865DB-5866-4285-A74D-168F45ED1109.

[6] I.-C. Wu, C.-C. Lin, and C. A. Hsiung, "Emerging roles of frailty and inflammaging in risk assessment of age-related chronic diseases in older adults: the intersection between aging biology and personalized medicine," BioMedicine, vol. 5, no. 1, p. 1, 2015, doi: 10.7603/s40681-0150001-1.

[7] D. T. Jamison, Disease Control Priorities, 3rd edition: improving health and reducing poverty, vol. 391, no. 10125. 2018.

[8] A. Sen, On Economic Inequality. Oxford: Clarendon Press, 1973.

[9] United Nations DPI, "Transforming Our World: 2030 Agenda for Sustainable Development Department of Public Information United Nations," 2016.

[10] A. Sen, "Poverty: An Ordinal Approach to Measurement," Econometrica, vol. 44, no. 2, p. 219, 1976, doi: 10.2307/1912718.

[11] L. R. and T. S. Anthony Atkinson, "Income Distribution in Advanced Economies: The Evidence from the Luxembourg Income Study (LIS)," 1994.

[12] R. Dimova and F. C. Wolff, "Are private transfers poverty and inequality reducing? Household level evidence from Bulgaria," J. Comp. Econ., vol. 36, no. 4, pp. 584-598, 2008, doi: 10.1016/j.jce.2008.05.002.

[13] H. S. Jung and E. Thorbecke, "The impact of public education expenditure on human capital, growth, and poverty in Tanzania and Zambia: A general equilibrium approach," J. Policy Model., vol. 25, no. 8, pp. 701-725, 2003, doi: 10.1016/S0161-8938(03)00060-7.

[14] A. R. Quisumbing, "Food aid and child nutrition in rural Ethiopia," World Dev., vol. 31, no. 7, pp. 1309-1324, 2003, doi: 10.1016/S0305-750X(03)00067-6.

[15] D. Parker, C. Kirkpatrick, and C. Figueira-Theodorakopoulou, "Infrastructure regulation and poverty reduction in developing countries: A review of the evidence and a research agenda," $Q$. Rev. Econ. Financ., vol. 48, no. 2, pp. 177-188, 2008, doi: 10.1016/j.qref.2006.12.005.

[16] R. Jha, T. Dang, and Y. Tashrifov, "Economic vulnerability and poverty in Tajikistan," Econ. Chang. Restruct., vol. 43, no. 2, pp. 95-112, 2010, doi: 10.1007/s10644-009-9079-3.

[17] J. Bronfman, "Measuring Vulnerability to Poverty in Chile Using the National Socio Economic Characterization Panel Survey for 1996, 2001, 2006," no. 62689, 2014.

[18] M. Grosh, J. Hoddinott, and A. Ahmed, "Targeting of transfers in developing countries : Review of experience and lessons The Targeting of Transfers in Developing Countries : Review of 
Experience and Lessons David Coady Margaret Grosh John Hoddinott November 2003,” 2003.

[19] A. Dabalen, T. Kilic, and W. Wane, "Social Transfers, Labor Supply and Poverty Reduction; The Case of Albania," 2008. [Online]. Available: http://econ.worldbank.org.

[20] O. Bargain, H. Immervoll, and H. Viitamäki, "No claim, no pain. Measuring the non-take-up of social assistance using register data," J. Econ. Inequal., vol. 10, no. 3, pp. 375-395, 2012, doi: 10.1007/s10888-010-9158-8.

[21] H. Jonathan and S. R. Khandker, Handbook on Poverty and Inequality. The World Bank, 2009.

[22] W. Naudé, A. U. Santos Paulino, and M. McGillivray, "MeasuringVulnerability: An Overview and Introduction," 2014.

[23] S. Klasen and H. Waibel, Vulnerability to Poverty-Theory, Measurement and Determinants, with Case Studies from Thailand and Vietnam, 1st ed. Palgrave Macmillan, London, 2013.

[24] P. S. Ward, "Transient Poverty, Poverty Dynamics, and Vulnerability to Poverty: An Empirical Analysis Using a Balanced Panel from Rural China," World Dev., vol. 78, pp. 541-553, 2016, doi: 10.1016/j.worlddev.2015.10.022.

[25] S. Chaudhuri, J. Jalan, and A. Suryahadi, "Assessing Household Vulnerability to Poverty from Cross-sectional Data: A Methodology and Estimates from Indonesia," World, vol. 0102-52, no. April, p. 36, 2002, [Online]. Available:

http://www.ncbi.nlm.nih.gov/entrez/query.fcgi?db=pubmed\&cmd=Retrieve\&dopt=AbstractPlus\& list_uids=6086807498683160254related:vpYxtyuveFQJ.

[26] E. Ligon and L. Schechter, "Measuring Vulnerability," Econ. J., vol. 113, no. 486, pp. C95-C102, Mar. 2003, doi: 10.1111/1468-0297.00117.

[27] A. Grech, "Evaluating the Possible Impact of Pension Reforms on Elderly Poverty in Europe," Soc. Policy Adm., vol. 49, no. 1, pp. 68-87, 2015, doi: 10.1111/spol.12084.

[28] L. Pritchett, A. Suryahadi, and S. Sumarto, "Quantifying Vulnerability to Poverty: A proposed measure applied to Indonesia," 2000. [Online]. Available: www.worldbank.org/research/workingpapers.

[29] J. Hoddinott and A. Quisumbing, "Data Sources for Microeconometric Risk and Vulnerability Assessments," 2003.

[30] S. Chaudhuri, "Assessing vulnerability to poverty : concepts, empirical methods and illustrative examples," Dep. Econ., p. 56, 2003, [Online]. Available:

http://info.worldbank.org/etools/docs/library/97185/keny_0304/ke_0304/vulnerabilityassessment.pdf.

[31] M. Ravallion and S. Chen, "China's (uneven) progress against poverty," J. Dev. Econ., vol. 82, no. 1, pp. 1-42, 2007, doi: 10.1016/j.jdeveco.2005.07.003.

[32] J. P. Ziliak, C. Gundersen, T. Smeeding, and J. Bartfeld, Eds., SNAP Matters: How Food Stamps Affect Health and Well-Being. Stanford: Stanford University Press, 2015.

[33] M. Celidoni, "Vulnerability to poverty: An empirical comparison of alternative measures," Appl. Econ., vol. 45, no. 12, pp. 1493-1506, 2013, doi: DOI: 10.1080/00036846.2011.624271.

[34] S. Dercon and P. Krishnan, "Vulnerability, seasonality and poverty in Ethiopia," J. Dev. Stud., vol. 36, no. 6, pp. 25-53, Aug. 2000, doi: 10.1080/00220380008422653.

[35] M. J. Bailey and S. Danziger, Eds., Legacies of the War on Poverty. Russell Sage Foundation, 2013.

[36] N. Kakwani and K. Subbarao, "Poverty among the elderly in Sub-Saharan Africa and the role of social pensions," J. Dev. Stud., vol. 43, no. 6, pp. 987-1008, Aug. 2007, doi: 10.1080/00220380701466476.

[37] O. Gloede, L. Menkhof, and H. Waibel, "Shocks, individual risk attitude, and vulnerability to poverty among rural households in Thailand and Vietna," Leibniz Univ. Hann. - Discuss. Pap., no. 0949-9962, p. No. 508, 2012.

[38] K. Hashimoto and J. A. Heath, "Income elasticities of educational expenditure by income class: The case of Japanese households," Econ. Educ. Rev., vol. 14, no. 1, pp. 63-71, 1995, doi: 10.1016/0272-7757(94)00030-A. 
[39] R. Andersen, “A behavioral model of families' use of health services," in Research Ser., No. 25., Chicago: Center for Health Administration Studies, University of Chicago, 1968, p. 111.

[40] S. Alkire and J. Foster, "Understandings and misunderstandings of multidimensional poverty measurement," J. Econ. Inequal., vol. 9, no. 2, pp. 289-314, 2011, doi: 10.1007/s10888-011-91814.

[41] Oxford Poverty \& Human Development Initiative, "Global Multidimensional Poverty Index 2020," 2020.

[42] Institute of Social Science Survey, "China Family Panel Studies," Peking University, 2021. http://www.isss.pku.edu.cn/cfps/ (accessed Mar. 30, 2021).

[43] L. J. Christiaensen and K. Subbarao, "Towards an understanding of household vulnerability in rural Kenya," J. Afr. Econ., vol. 14, no. 4, pp. 520-558, 2005, doi: 10.1093/jae/eji008.

[44] T. Amemiya, "The Maximum Likelihood and the Nonlinear Three-Stage Least Squares Estimator in the General Nonlinear Simultaneous Equation Model," Econometrica, vol. 45, no. 4, pp. 955968, Jul. 1977, doi: 10.2307/1912684.

[45] The World Bank, Piecing Together the Poverty Puzzle. 2018.

[46] W. Cao, X. Feng, and H. Zhang, "The structural and spatial properties of the high-speed railway network in China: A complex network perspective," J. Rail Transp. Plan. Manag., vol. 9, pp. 4656, 2019, doi: https://doi.org/10.1016/j.jrtpm.2018.10.001.

[47] T. Chen, Y. Wang, X. Luo, Y. Rao, and L. Hua, "Inter-provincial inequality of public health services in China: the perspective of local officials' behavior," Int. J. Equity Health, vol. 17, no. 1, p. 108, 2018, doi: 10.1186/s12939-018-0827-8.

[48] J. Novignon, J. Nonvignon, R. Mussa, and L. S. Chiwaula, "Health and vulnerability to poverty in Ghana: Evidence from the Ghana living standards survey round 5," Health Econ. Rev., vol. 2, no. 1, pp. 1-9, 2012, doi: 10.1186/2191-1991-2-11.

[49] S. Chen, J. Li, S. Lu, and B. Xiong, "Escaping from poverty trap: a choice between government transfer payments and public services," Glob. Heal. Res. Policy, vol. 2, no. 1, pp. 1-16, 2017, doi: 10.1186/s41256-017-0035-x.

[50] P. Lavrakas, "Encyclopedia of Survey Research Methods." Thousand Oaks, California, 2008, doi: 10.4135/9781412963947 NV - 0.

[51] S. Chen, J. Li, S. Lu, and B. Xiong, "Escaping from poverty trap: a choice between government transfer payments and public services," Glob. Heal. Res. Policy, vol. 2, no. 1, p. 15, 2017, doi: 10.1186/s41256-017-0035-x.

[52] M. Wang, W. Kang, and R. Zhang, "The Gap between Urban and Rural Development Levels Narrowed," Complexity, vol. 2020, p. 4615760, 2020, doi: 10.1155/2020/4615760.

[53] T. Dubikaytis, M. Larivaara, O. Kuznetsova, and E. Hemminki, "Inequalities in health and health service utilisation among reproductive age women in St. Petersburg, Russia: a cross-sectional study," BMC Health Serv. Res., vol. 10, no. 1, p. 307, 2010, doi: 10.1186/1472-6963-10-307.

[54] X. Lan et al., "Assessing the effects of the percentage of chronic disease in households on health payment-induced poverty in Shaanxi Province, China," BMC Health Serv. Res., vol. 18, no. 1, pp. 1-9, 2018, doi: 10.1186/s12913-018-3698-1.

[55] C. H. Gong, H. Kendig, and X. He, "Factors predicting health services use among older people in China: An analysis of the China Health and Retirement Longitudinal Study 2013," BMC Health Serv. Res., vol. 16, no. 1, pp. 1-16, 2016, doi: 10.1186/s12913-016-1307-8. 


\section{Supplementary Files}

This is a list of supplementary files associated with this preprint. Click to download.

- Supplementaryfile.xlsx 